\title{
Efeito inseticida sistêmico de nanoformulações à base de nim sobre Bemisia tabaci (Hemiptera: Aleyrodidae) biótipo B em tomateiro
}

\author{
Sheila Salles de Carvalho $\left({ }^{1 *}\right)$; José Djair Vendramim ( $\left.{ }^{1}\right)$; Israel Cívico Gil de Sá $\left({ }^{2}\right)$; \\ Maria Fátima das Garças Fernandes da Silva $\left({ }^{2}\right)$; Leandro do Prado Ribeiro ( $\left.{ }^{3}\right)$; Moacir Rossi Forim ( ${ }^{2}$ ) \\ (1) Universidade de São Paulo (USP), Escola Superior de Agricultura “Luiz de Queiroz” (ESALQ), \\ Departamento de Entomologia e Acarologia, Avenida Pádua Dias, 11, 13418-900 Piracicaba (SP), Brasil. \\ (2) Universidade Federal de São Carlos (UFSCar), Departamento de Química, Caixa Postal 676, 13565-905 São Carlos (SP), Brasil. \\ (3) Empresa de Pesquisa Agropecuária e Extensão Rural de Santa Catarina (EPAGRI), Centro de Pesquisa para Agricultura Familiar, \\ Caixa Postal 251, 89812-110 Chapecó (SC), Brasil.
}

(*) Autora correspondente: sscarval@gmail.com

Recebido: 13/nov./2014; Aceito: 30/mar./2015

Resumo

Este estudo avaliou a ação inseticida sistêmica e o efeito residual de nanoformulações à base de derivados de nim (Azadirachta indica A. Juss, Meliaceae) sobre ninfas de Bemisia tabaci biótipo B (Hemiptera: Aleyrodidae), espécie-praga de diversas culturas de importância econômica. Suspensões coloidais contendo nanocápsulas carregadas com produtos derivados de $A$. indica

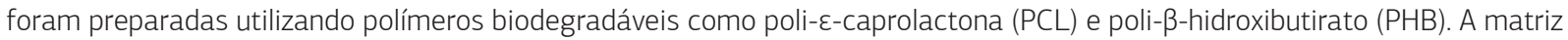
encapsulada era composta por uma formulação comercial contendo uma quantidade enriquecida e conhecida dos limonoides azadiractina e 3-tigloilazadiractol (Azamax ${ }^{\circledR}$ 1,2 CE). Inicialmente foi estimada a $\mathrm{CL}_{50}$, para ninfas de $B$. tabaci, de soluções contendo óleo de nim, que foram aplicadas via água de irrigação (solo) em tomateiro. Posteriormente, dois lotes de nanoformulações, com variação no tipo e quantidade dos polímeros e na quantidade do óleo comercial, foram testados quanto à ação sistêmica. As nanoformulações NC L5-2 (com nanocápsulas de PCL) e NC L6-1 (com nanocápsulas de PHB), as mais eficazes entre as

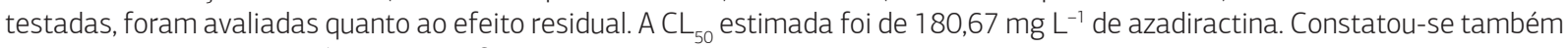
que a ação sistêmica de óleos e nanoformulações contendo compostos de nim dependem das condições ambientais em que são aplicados. O Azamax ${ }^{\circledR}$ não apresenta efeito deterrente sobre a oviposição, nem age sobre o desenvolvimento embrionário da mosca-branca quando aplicado via água de irrigação no solo no momento da infestação. As nanoformulações selecionadas são bioativas mesmo cerca de 30 dias após a aplicação, não diferindo do produto comercial.

Palavras-chave: nanotecnologia, bioatividade, MIP, Azadirachta indica.

\section{Systemic insecticidal effect of neem-based nanoformulations against Bemisia tabaci (Hemiptera: Aleyrodidae) biotype B in tomato}

\begin{abstract}
This study evaluated the systemic insecticidal action and the residual effect of neem-based nanoformulations (Azadirachta indica A. Juss, Meliaceae) on Bemisia tabaci biotype B (Hemiptera: Aleyrodidae) nymphs, a pest of several economic important crops. Colloidal suspensions containing nanocapsules loaded with derived products from $A$. indica were prepared by using biodegradable polymers such as poly- $\varepsilon$-caprolactone $(\mathrm{PCL})$ and poly- $\beta$-hydroxybutyrate $(\mathrm{PHB})$. The encapsulated matrix was a commercial formulation, which contained not only enriched amount of limonoids azadirachtin and 3-tigloilazadiractol, but also in known quantities (Azamax ${ }^{\circledR} 1.2 \mathrm{CE}$ ). Initially, it was estimated the LC $_{50}$ of solutions containing neem oil, which were applied through irrigation water (soil) in tomato in order to control nymphs of B. tabaci. Afterwards, two lots of nanoformulations, varying in type and amount of polymers and in quantity of commercial oil, were evaluated for systemic action. The nanoformulations NC L5-2 (nanocapules in PCL) and NC L6-1 (nanocapsules in PHB) caused higher mortality among others and for this reason were assayed for residual effect. The estimated value for $L C_{50}$ was $180.67 \mathrm{mg} \mathrm{L}^{-1}$ of azadirachtin. The results showed that systemic action of oils and nanoformulations containing neem compounds depends on environmental conditions. Azamax ${ }^{\circledR}$ did not show either deterrent effect of oviposition or effect on whitefly embryogenesis when applied in soil irrigation at the time of infestation. The nanoformulations selected are bioactives even about 30 days after application and do not differ of commercial product.
\end{abstract}

Key words: nanotechnology, bioactivity, IPM, Azadirachta indica. 


\section{INTRODUÇÃO}

Muitas investigações têm sido conduzidas visando detectar novas fontes de bioinseticidas para controle de pragas em plantas cultivadas e em produtos armazenados (Amoabeng et al., 2013; Ribeiro et al., 2013, 2014). No entanto, apesar da crescente demanda por produtos mais seletivos e seguros (Isman et al., 2011), poucas formulaçôes têm sido desenvolvidas e disponibilizadas no mercado mundial (Isman \& Greineisen, 2014).

$\mathrm{O}$ nim, Azadirachta indica A. Juss (Meliaceae), é a planta inseticida mais conhecida e utilizada, e algumas formulaçôes à base de extratos orgânicos (enriquecidos ou não), de óleos brutos ou de limonoides purificados de suas sementes encontram-se disponíveis no mercado de diferentes países. De modo geral, a bioatividade de derivados de nim sobre artrópodes-praga é decorrente do sinergismo de diferentes compostos (especialmente limonoides), sendo o triterpenoide azadiractina o componente ativo majoritário (Sundaram, 1996). Limonoides de A. indica ocasionam diversos efeitos agudos e crônicos sobre artrópodes-praga, incluindo inibição alimentar, alongamento da duração da fase imatura, redução da fecundidade e fertilidade, alteraçôes comportamentais e anomalias celulares, além de causarem significativa mortalidade nos diferentes estágios de desenvolvimento (Martinez, 2011; Mordue (Luntz) \& Blackwell, 1993; Schmutterer, 1990). Apesar da ampla gama de efeitos biológicos ocasionados por esses limonoides, o fato de serem fotoinstáveis e termolábeis tem limitado a eficácia das formulaçóes comercializadas a campo (Stokes \& Redfern, 1982), exigindo reaplicaçóes em curtos intervalos ( - 5-7 dias), onerando os custos de produção.

Uma das soluçôes para contornar esse problema é o encapsulamento dos compostos naturais em escala nanométrica (Perlatti et al., 2013), o que, além de aumentar o efeito residual, possibilita o controle da liberação do ingrediente ativo (Devi \& Maji, 2011), permitindo melhorar a eficiência e a persistência dos biopesticidas (Mattoso et al., 2005). Polímeros biodegradáveis têm sido utilizados com sucesso como agentes encapsulantes, entre eles a poli- $\varepsilon$-caprolactona (PCL) e o poli- $\beta$-hidroxibutirato (PHB) (Ferreira et al., 2012). No entanto, para sua aplicação em escala comercial, ainda há necessidade de estudos que visem avaliar a eficácia dos ingredientes encapsulados sobre as espécies-alvos e a cinética de liberação dos ingredientes ativos em condiçóes de semicampo e campo.

Outra forma de minimizar a baixa persistência de inseticidas botânicos é a redução de sua exposição aos fatores de degradação (especialmente a radiação ultravioleta) por meio de sua aplicação via água de irrigação (solo). De acordo com Souza \& Vendramim (2005), a aplicação via irrigação do nim pode aumentar sua persistência em comparação à aplicação foliar, em que ocorre rápida degradação das substâncias ativas ( -6 dias). No que se refere ao nim, entretanto, faltam conhecimentos sobre essa forma de aplicação para manejo de artrópodes-praga.

Entre os insetos que se busca controlar com a aplicação de extratos botânicos, inclui-se a mosca-branca Bemisia tabaci (Genn., 1889) biótipo B, um hemíptero da família Aleyrodidae que se alimenta no floema e causa danos diretos e indiretos às plantas. Em tomateiro, os danos diretos estáo relacionados à sucção de seiva, injeção de toxinas, que provoca o amadurecimento irregular dos frutos, os quais se tornam internamente esbranquiçados e com aspecto esponjoso, e a liberação de uma substância açucarada (honeydew) provocando a proliferação do fungo Capnodium sp. (fumagina), o que diminui a área fotossintética da planta e, consequentemente, sua produtividade. Os danos indiretos são relacionados à transmissão de geminivírus, causando geralmente clorose entre as nervuras na base do folíolo, que evolui para um mosaico-amarelo, sintomas que se generalizam por toda a planta e são seguidos por intensa rugosidade dos folíolos (Villas-Bôas et al., 1997).Nesse contexto, avaliou-se a ação inseticida sistêmica e o efeito residual de nanoformulaçôes à base de derivados de nim, contendo os polímeros poli- $\varepsilon$-caprolactona (PCL) e poli- $\beta$-hidroxibutirato (PHB) como agentes encapsulantes, sobre a mosca-branca $B$. tabaci biótipo $\mathrm{B}$, praga de grande importância econômica para o cultivo de tomateiro na América tropical.

\section{MATERIAL E MÉTODOS}

\section{Preparo de nanoformulações}

Nanocápsulas foram preparadas por meio do processo de deslocamento de solvente/deposição interfacial (Forim et al., 2013), utilizando dois tipos de polímeros como agentes encapsulantes: poli- $\beta$-hidroxibutirato (PHB) e poli-e-caprolactona (PCL) (Tabela 1). A formulação comercial enriquecida com os limonoides azadiractina e 3-tigloilazadiractol (Azamax ${ }^{\circledR}$ 1.2 CE, UPL Brasil Ltda, Campinas, SP, Brasil) foi utilizada como matriz oleosa das nanocápsulas. Essa formulação está registrada para manejo de B. tabaci na tomaticultura brasileira (Brasil, 2014).

A quantificação do teor de azadiractina no óleo de nim, no produto comercial utilizado e nas nanoformulaçóes obtidas, foi realizada por meio de cromatografia líquida de alta eficiência acoplada ao detector ultravioleta (HPLCUV, Agilent Technologies 1260 Series), conforme descrito por Forim et al. $(2010,2013)$. A faixa linear de trabalho usada para quantificação de azadiractina nas diferentes matrizes foi obtida pela análise de soluçóes-padrão em concentraçôes variando de 1 a $100 \mu \mathrm{g} \mathrm{mL}^{-1}$. Foi utilizada uma coluna analítica Agilent Eclipse XDB- $\mathrm{C}_{18}(150 \times 4,6 \mathrm{~mm}$, $5 \mu \mathrm{m}-\mathrm{S} / \mathrm{N}$ USKH040659), acoplada a uma coluna de segurança C18 (Phemonemex ${ }^{\circledR}-4 \times 3 \mathrm{~mm}$ ), com uma vazão de 
Tabela 1. Descrição das nanoformulaçóes à base de derivados de nim produzidas através do processo de deslocamento de solvente/deposição interfacial (Forim et al., 2013), utilizando dois tipos de agentes encapsulantes: poli- $\beta$-hidroxibutirato (PHB) e poli- $\varepsilon$-caprolactona (PCL)

\begin{tabular}{|c|c|c|}
\hline $\begin{array}{l}\text { Nanoformulações } \\
\text { (nanocápsulas) }\end{array}$ & Composição & $\begin{array}{c}\text { Teor de } \\
\text { azadiractina } \\
\left(\mathrm{mg} \mathrm{L}^{-1}\right)\end{array}$ \\
\hline \multicolumn{3}{|c|}{ Lote 1 (PCL) } \\
\hline NC L5-1 & $\begin{array}{l}\text { PCL } 60000 \text { (0,8 g) } \\
\text { Extrato EtOH }(5,0 \mathrm{~g}) \\
\text { Óleo Azamax }(4,0 \mathrm{~g}) \\
\text { Tween } 80(0,8 \mathrm{~g})\end{array}$ & 633 \\
\hline NC L5-2 & $\begin{array}{l}\text { PCL } 60000(0,8 \mathrm{~g}) \\
\text { Extrato EtOH }(2,0 \mathrm{~g}) \\
\text { Óleo Azamax }{ }^{\circledR}(8,0 \mathrm{~g}) \\
\text { Tween } 80(0,8 \mathrm{~g})\end{array}$ & 453,2 \\
\hline Branco NC L5 & $\begin{array}{c}\text { PCL } 60000(0.8 \mathrm{~g}) \\
\text { Oleato de isodecila } \\
(4,0 \mathrm{~g}) \\
\text { Tween } 80(0,8 \mathrm{~g})\end{array}$ & - \\
\hline \multicolumn{3}{|c|}{ Lote 2 (PHB) } \\
\hline NC L6-1 & $\begin{array}{c}\text { PHB }(1,0 \mathrm{~g}) \\
\text { Extrato EtOH }(4,3 \mathrm{~g}) \\
\text { Óleo Azamax }{ }^{\circledR}(6,0 \mathrm{~g}) \\
\text { Tween } 80(0,8 \mathrm{~g}) \\
\text { SPAN } 60(0,6 \mathrm{~g})\end{array}$ & 753 \\
\hline NC L6-2 & $\begin{array}{c}\text { PHB }(0,75 \mathrm{~g}) \\
\text { Extrato EtOH }(2,0 \mathrm{~g}) \\
\text { Óleo Azamax }(4,0 \mathrm{~g}) \\
\text { Tween } 80(0,8 \mathrm{~g})\end{array}$ & 300 \\
\hline NC L6-3 & $\begin{array}{c}\text { PHB }(0,5 \mathrm{~g}) \\
\text { Extrato EtOH }(2,0 \mathrm{~g}) \\
\text { Óleo Azamax }{ }^{\circledast}(4,0 \mathrm{~g}) \\
\text { Tween } 80(0,8 \mathrm{~g})\end{array}$ & 230 \\
\hline NC L6-4 & $\begin{array}{c}\text { PHB }(0,25 \mathrm{~g}) \\
\text { Extrato EtOH }(2,0 \mathrm{~g}) \\
\text { Óleo Azamax }(4,0 \mathrm{~g}) \\
\text { Tween } 80(0,8 \mathrm{~g})\end{array}$ & 268 \\
\hline Branco NC L6 & $\begin{array}{c}\mathrm{PHB}(1,0 \mathrm{~g}) \\
\text { Oleato de isodecila } \\
(4,0 \mathrm{~g}) \\
\text { Tween } 80(0,8 \mathrm{~g})\end{array}$ & - \\
\hline
\end{tabular}

1,0 mL min ${ }^{-1}$, modo de eluição isocrático $\mathrm{ACN} / \mathrm{H}_{2} \mathrm{O} 35: 65$, volume de injeção de $10 \mu \mathrm{L}$ e leitura num comprimento de onda de detecção fixo de $217 \mathrm{~nm}$ (limite máximo de absorção da azadiractina).

\section{Criação estoque de Bemisia tabaci biótipo B}

A população de $B$. tabaci foi obtida no Setor de Entomologia do Instituto Agronômico de Campinas (IAC), sendo a confirmação do biótipo realizada pelo Prof. Dr. Aurino Florêncio de Lima (Universidade Federal Rural do Rio de Janeiro, Seropédica/RJ).

Para manutenção da população do inseto, plantas de soja (Glycine max L. Merryl) cv. CD-215, de tomateiro (Solanum lycoperscicum L.) cv. Santa Clara e de couve-comum (Brassica oleracea var. acephala D.C.) cv. Manteiga foram utilizadas como substratos de oviposição e alimentação de ninfas e adultos. Essas plantas foram mantidas em gaiolas de aproximadamente $2,5 \mathrm{~m}^{2} \mathrm{com}$ armação de ferro e tela antiafídica $(0,2 \times 0,2 \mathrm{~mm})$, visando evitar a fuga dos insetos adultos.

\section{Bioensaios}

Os bioensaios foram conduzidos em casa de vegetação coberta com filme plástico e manta termorrefletora de aluminete, na qual as condiçóes climáticas, durante cada bioensaio, foram mensuradas por meio de um data-logger modelo TGU-4500 (Tinytag Gemini Dataloggers Ltda., Chichester, West Sussex, Reino Unido).

Plantas de tomateiro cv. Santa Clara cultivadas em potes plásticos $(0,5 \mathrm{~L})$ foram utilizadas como unidades experimentais. Uma mistura de substrato comercial para hortaliças (Basaplant ${ }^{\circledR}$, Base Agro Ltda., Artur Nogueira, SP, Brasil), vermiculita e terra de barranco [3:2:1 (v/v/v)] foi usada como substrato de cultivo. Antes da utilização nos vasos, a mistura foi corrigida com NPK 4:14:8 e calcário calcítico, em doses definidas com base em análises prévias.

\section{Estimativa da $\mathrm{CL}_{50}$ do óleo de nim via água de irrigação (solo)}

Para definir a concentração de azadiractina a ser empregada nos testes subsequentes com as nanoformulações, uma curva de concentraçáa-resposta foi obtida com óleo de nim produzido em laboratório a partir de sementes a fim de estimar a $\mathrm{CL}_{50}$ (em $\mathrm{mg}$ de azadiractina por $\mathrm{L}^{-1}$ ) para as ninfas de B. tabaci expostas ao óleo. Plantas com quatro folhas compostas (sem considerar o primeiro par dismorfo) foram selecionadas para a condução do ensaio. Gaiolas $(15 \mathrm{~cm}$ de comprimento $\times 6 \mathrm{~cm}$ de diâmetro) confeccionadas com voile foram dispostas sobre dois folíolos apicais por planta, uma na segunda e outra na quarta folha. Infestou-se cada folha selecionada com 30 adultos não sexados, oriundos da criação estoque, os quais foram mantidos sobre as plantas por um período de 24 horas para oviposição. Decorrido esse período, as gaiolas foram retiradas e os adultos, removidos dos folíolos. A soma das ninfas obtidas nos dois folíolos infestados foi considerada uma repetição. Efetuaram-se cinco repetiçóes (plantas) para cada tratamento.

Após a eclosão e fixação das ninfas de primeiro ínstar ( 14 dias após a oviposiçáo), determinou-se o número de indivíduos na face abaxial de cada folíolo com auxílio de um microscópio estereoscópico (aumento de 10 a 15 vezes). Ao óleo de nim, foram adicionados os tensoativos Renex ${ }^{\circledR}$ e Extravon ${ }^{\circledR} 0,2 \%$ na proporçáo de $5 \%$ cada, a fim de melhorar a solubilidade e estabilidade das soluçóes aquosas a serem aplicadas. Os tratamentos foram constituídos por quatro concentraçôes do óleo de nim, correspondentes aos 
teores de azadiractina de 37,8; 75,6; 151,2 e 302,4 $\mathrm{mg} \mathrm{L}^{-1}$, as quais foram definidas com base em testes preliminares (Finney, 1971). Como controle negativo, usou-se água deionizada acrescida dos referidos tensoativos. Ensaios preliminares mostraram que os tensoativos, quando aplicados no solo, não afetam a sobrevivência das ninfas.

A aplicação dos tratamentos foi realizada sobre o solo na base de cada planta, na dose de $20 \mathrm{~mL}$ de soluçáo por planta, volume determinado com base em testes preliminares de modo a evitar o escorrimento de solução. Durante o ensaio, as plantas foram irrigadas com $30 \mathrm{~mL}$ de água deionizada sempre que apresentavam sinais de murcha, porém evitando o escorrimento de soluçáa.

A mortalidade das ninfas foi avaliada após sete dias, com auxílio de microscópio estereoscópico (aumento de 7 a 10 vezes). Foram consideradas mortas as ninfas que apresentavam tamanho reduzido $(-0,25 \times 0,15 \mathrm{~mm})$ e formato elíptico semelhante às de primeiro instar (Eichelkraut $\&$ Cardona, 1989; Patel et al., 1992), ou mesmo quando elas se apresentavam murchas e/ou com coloraçáo escura ou alaranjada.

\section{Bioatividade de Azamax ${ }^{\circledR}$ 1.2 CE via água de irrigação (solo)}

Com base na $\mathrm{CL}_{50}$ estimada anteriormente para o óleo de nim (em $\mathrm{mg} \mathrm{L}^{-1}$ de azadiractina), foram avaliadas, em teste sem chance de escolha, algumas variáveis biológicas (oviposição, viabilidade de ovos e mortalidade de ninfas) após a aplicação de Azamax ${ }^{\circledR} 1.2 \mathrm{CE}$, via água de irrigação. Para isso, os mesmos procedimentos descritos no bioensaio anterior foram adotados, utilizando-se para cada tratamento [bioinseticida e controle negativo (água deionizada)] dez repetiçóes (plantas).

Para a infestação das plantas, foram coletados 30 adultos quando se encontravam pareados (Byrne \& Bellows, 1991) sobre planta hospedeira, ou seja, 15 casais. Estes foram liberados nas gaiolas de voile previamente acopladas ao folíolo apical da terceira folha composta (excluindo o primeiro par dismorfo) de cada planta. $\mathrm{Na}$ casa de vegetaçáo, os grupos de plantas dos dois tratamentos foram acondicionados sobre a bancada e ficaram separados por uma barreira de plantas não tratadas até o final do período de infestação, a fim de evitar que voláteis do produto comercial à base de limonoides pudessem eventualmente interferir na oviposiçáo das fêmeas de B. tabaci expostas ao tratamento controle. Após 24 horas, as gaiolas com os adultos foram retiradas e as plantas distribuídas aleatoriamente (sem barreiras) sobre as bancadas. O número de ovos depositados nas faces adaxial e abaxial dos folíolos foi contado com auxílio de microscópio estereoscópico (aumento de 10 a 15 vezes). Dez dias após a aplicação, foi avaliada a eclosão das ninfas e, após 22 dias da aplicaçáo, avaliou-se a mortalidade destas.

\section{Seleção de nanoformulações}

Os mesmos procedimentos e unidades experimentais descritos anteriormente foram utilizados para este ensaio. As nanoformulaçóes obtidas foram testadas separadamente em dois lotes [lotes 1 (PCL) e 2 (PHB)], dispersas em água deionizada e aplicadas sobre o solo na base de cada planta $\left(20 \mathrm{~mL}\right.$ planta $\left.^{-1}\right)$. Como houve variaçấo no teor de azadiractina nas nanoformulaçóes produzidas, a quantidade de nanopartículas usadas para o preparo das suspensōes coloidais estudadas foi ajustada em relação ao teor equivalente ao determinado na $\mathrm{CL}_{50}$ estimada previamente (mg de azadiractina $\mathrm{L}^{-1}$ ) para o óleo de nim. Os controles negativos foram água deionizada (utilizada na dispersão das nanoformulaçóes) e os brancos das nanoformulaçôes (nanopartículas em suspensões coloidais preparadas contendo o polímero e os demais componentes das nanoformulaçóes, exceto os ingredientes ativos), os quais também foram diluídos em água. A solução com o branco das nanoformulaçóes em PCL foi preparada usando o mesmo volume da NC L5-1, enquanto para o branco das nanoformulações em PHB utilizou-se o mesmo volume da NC L6-1. Como controle positivo, foi usada a formulação Azamax $^{\circledR}$ 1,2 CE, na $\mathrm{CL}_{50}$ estimada previamente para o óleo de nim, ajustada em relação aos seus respectivos teores de azadiractina.

Após 5, 10 e 15 dias da aplicaçáo dos tratamentos, as ninfas mortas foram contadas e retiradas dos folíolos com alfinete entomológico. O número de repetiçóes por tratamento foi diferente nos dois ensaios, sendo cinco para as nanocápsulas em PCL e quatro para as nanocápsulas em PHB. A infestação dos adultos e a caracterização da unidade amostral (repetiçáo) foram feitas conforme descrito no ensaio para estimativa da $\mathrm{CL}_{50}$.

\section{Efeito residual das nanoformulações}

Para avaliar o efeito residual, foi selecionada a formulação mais promissora em cada lote (em PCL e em PHB). Os controles negativos foram água deionizada (utilizada na dispersão das nanoformulaçóes) e os brancos das nanoformulaçôes, também dispersos em água deionizada. A solução com o branco das nanoformulações em PCL foi preparada usando o mesmo volume da NC L5-2, enquanto para o branco das nanoformulaçóes em PHB utilizou-se o mesmo volume da NC L6-1. Como controle positivo, foi usada a formulação Azamax ${ }^{\circledR}$ 1,2 CE, na $\mathrm{CL}_{50}$ estimada previamente para o óleo de nim, ajustadas em relaçáo aos teores relativos de azadiractina.

Para padronização das plantas no momento da infestação, a semeadura ocorreu de forma escalonada, com intervalos de cinco dias, totalizando cinco lotes de plantas. Decorridos 15 dias da semeadura, as mudas foram transplantadas para potes plásticos $(0,5 \mathrm{~L})$ e a infestação das plantas (conforme 
descrito nos ensaios anteriores) também ocorreu com intervalos de cinco dias, seguindo a ordem de semeadura. Dez dias após a infestação do primeiro lote de plantas, correspondendo, portanto, ao dia da infestação do terceiro lote, os tratamentos foram aplicados no solo junto à base de cada planta dos cinco lotes. Desse modo, as infestaçôes do quarto e do quinto lotes ocorreram cinco e dez dias após a aplicação, respectivamente. Para cada lote, o número de ninfas na face abaxial dos folíolos foi contado dez dias após a respectiva infestação.

Foram realizadas cinco repetiçóes (soma dos dois folíolos infestados de uma planta) para cada tratamento em cada lote. As avaliaçōes de mortalidade ninfal foram realizadas aos 22 dias após a infestação de cada lote de plantas. Assim, a última avaliação (quinto lote) foi feita 32 dias após a aplicaçáo dos tratamentos.

\section{Análise estatística}

Todos os ensaios foram conduzidos em delineamento inteiramente casualizado. Os dados de proporçáo de mortalidade foram transformados em arco seno [raiz (mortalidade+1)], de modo a satisfazer os pressupostos para análise de variância (normalidade dos erros e homogeneidade de variâncias). Quando houve diferença significativa entre os tratamentos (Teste F), as médias foram comparadas pelo teste $\mathrm{t}$ nos ensaios com dois tratamentos ou pela correção de Bonferroni seguida de teste $\mathrm{t}$ nos demais casos. Em todas as análises, foi utilizado o programa SAS 9.3 (SAS Institute, 2011). Para a estimativa da $\mathrm{CL}_{50}$, os dados foram submetidos à análise de Probit (Finney, 1971), usando o software POLO-PC (Leora Software, 1987).

\section{RESULTADOS E DISCUSSÃO}

\section{Estimativa da $\mathrm{CL}_{50}$ do óleo de nim via água de irrigação (solo)}

O óleo de nim aplicado via água de irrigação (solo) causou significativa mortalidade de ninfas de B. tabaci biótico B de modo dependente da concentração $\left[\mathrm{CL}_{50}=180,67 \mathrm{mg}\right.$ de azadiractina $\mathrm{L}^{-1}$ (Tabela 2)]. Tal resultado corrobora outros estudos (Prabhaker et al., 1999; Souza \& Vendramim, 2005), que também demonstraram a ação inseticida sistêmica de derivados de sementes de nim.
Por meio de aplicação foliar, Carvalho et al. (2012) estimaram uma $\mathrm{CL}_{50}$ de $1,6 \mathrm{mg}$ de azadiractina $\mathrm{L}^{-1}$ para ninfas de $B$. tabaci biótico $\mathrm{B}$ a partir de uma formulação comercial à base de óleo de nim $\left(\right.$ Organic $\left.\mathrm{Neem}^{\circledR}\right)$, valor muito inferior ao verificado no presente estudo. Além das diferenças qualitativas e quantitativas das formulaçóes testadas em ambos os estudos (especialmente a ocorrência e o teor de compostos ativos minoritários), a capacidade de sorção dos compostos ativos no substrato, ou mesmo o tempo necessário para translocaçáo até os folíolos do terço superior do tomateiro, sítio preferencial de oviposição e alimentação de B. tabaci biótipo B (Toscano et al., 2002), pode explicar tais diferenças nas CLs estimadas para as duas formas de aplicação do nim. Cabe salientar, no entanto, que, apesar das maiores concentraçôes requeridas para controle efetivo dessa praga em tomateiro via água de irrigação (solo), a maior persistência da ação inseticida e a seletividade ecológica condicionada por essa forma de aplicação provavelmente compensem o uso de uma maior quantidade de composto ativo.

\section{Bioatividade de Azamax ${ }^{\circledR}$ 1.2 CE via água de irrigação (solo)}

O inseticida botânico Azamax ${ }^{\circledR}$ 1,2 CE, na $\mathrm{CL}_{50}$ estimada previamente para o óleo de nim, não ocasionou efeito deterrente de oviposiçáo ou mesmo açáo sobre o desenvolvimento embrionário de $B$. tabaci biótipo $\mathrm{B}$, quando aplicado via água de irrigação (solo) (Tabela 3). Diferentemente dos resultados aqui apresentados, Prabhaker et al. (1999) observaram redução na oviposição e na porcentagem de eclosão de ninfas de B. tabaci biótipo $B$ em plantas de algodoeiro tratadas com soluçóes contendo extratos de sementes de nim via substrato de cultivo. Além das diferenças relacionadas às formulaçóes dos derivados de nim utilizados, os autores infestaram as plantas 48 horas após a aplicaçáo dos tratamentos, diferentemente do presente estudo (infestação 24 horas após a aplicação). Nesse sentido, o tempo necessário para os compostos ativos se deslocarem através das plantas e atingirem as folhas do terço superior, substrato preferido para a oviposição das fêmeas, pode ser uma das razóes para as diferenças apresentadas. Em adição, a maior atividade metabólica (taxa de transpiração e fotossíntese) do algodoeiro em comparação ao tomateiro, em hipótese, condicionadas por fatores genéticos associados ou não às condiçôes do ambiente (tais como temperatura e luminosidade, entre outros) pode também ter contribuído

Tabela 2. Estimativa da $\mathrm{CL}_{50}$ (em mg de azadiractina $\mathrm{L}^{-1}$ ) e intervalo de confiança do óleo de nim para ninfas de primeiro instar de Bemisia tabaci biótipo B via água de irrigação (solo). Temperatura: $28,6 \pm 6,21^{\circ} \mathrm{C}$, UR: $36 \% \pm 12,68 \%$ e fotofase de $11 \mathrm{~h} 40$

\begin{tabular}{|c|c|c|c|c|c|}
\hline$n^{1}$ & Coeficiente angular \pm EP & $\mathrm{CL}_{50}(\mathrm{IC} 95 \%)^{2}$ & $x^{2(3)}$ & g.l. ${ }^{4}$ & h. ${ }^{5}$ \\
\hline 920 & $3,11 \pm 0,22$ & $180,67(164,1-198,37)$ & 1,62 & 2 & 0,81 \\
\hline
\end{tabular}


Tabela 3. Médias ( \pm erro padrão) do número de ovos e do número de ninfas de Bemisia tabaci biótipo B eclodidas em folíolos de tomateiro, aos 22 dias após a aplicação de uma formulação à base de limonoides (Azamax ${ }^{\circledR} 1,2 \mathrm{CE}$ ) via água de irrigação (solo). Temperatura: $27,45 \pm 0,18^{\circ} \mathrm{C}$, UR: $65,45 \pm 0,47 \%$ e fotofase de 13,5 horas

\begin{tabular}{|c|c|c|}
\hline \multirow[b]{2}{*}{ Variáveis analisadas } & \multicolumn{2}{|c|}{ Tratamentos } \\
\hline & Controle & $\begin{array}{c}\text { Azamax }^{\circledR} \\
\text { EC }\end{array}$ \\
\hline № de ovos (superfície adaxial) ns & $13,7 \pm 2,42$ & $14,1 \pm 2,51$ \\
\hline No de ovos (superfície abaxial) ns & $63,6 \pm 9,08$ & $56,3 \pm 6,35$ \\
\hline No total de ovos no folíolons & $77,3 \pm 8,38$ & $70,4 \pm 6,84$ \\
\hline $\begin{array}{l}\text { No de ninfas eclodidas (superfície } \\
\text { adaxial) ns }\end{array}$ & $13,5 \pm 2,41$ & $14,1 \pm 2,51$ \\
\hline $\begin{array}{l}\text { No de ninfas eclodidas (superfície } \\
\text { abaxial) ns }\end{array}$ & $63,2 \pm 9,19$ & $55,4 \pm 6,35$ \\
\hline$N^{0}$ total de ninfas eclodidas ${ }^{n s}$ & $76,7 \pm 8,46$ & $69,5 \pm 6,79$ \\
\hline Eclosão $(\%)^{\text {ns }}$ & $99,0 \pm 0,46$ & $98,8 \pm 0,80$ \\
\hline Mortalidade ninfal acumulada (\%) ${ }^{1}$ & $6,2 \pm 1,53 b$ & $43,9 \pm 6,73 \mathrm{a}$ \\
\hline
\end{tabular}

para uma maior velocidade de deslocamento dos componentes ativos, fato a ser ainda investigado em futuros estudos.

Azamax $^{\circledR}$ 1,2 CE ocasionou, no entanto, significativa mortalidade de ninfas de B. tabaci biótipo $\mathrm{B}$ expostas às plantas tratadas via água de irrigação (Tabela 3) em comparação às plantas controle, sugerindo que os componentes inseticidas da formulação podem permanecer ativos no interior da planta do tomateiro após vários dias de sua aplicação. Não foi possível separar, durante as avaliaçóes, a mortalidade das ninfas em função da localização nas faces adaxial e abaxial da folha, pois muitas delas migraram de face após a eclosão, uma vez que, quando contadas novamente na face adaxial, o número havia reduzido, razão pela qual foi considerada apenas a mortalidade total nos folíolos. Todavia, diferenças na acumulação dos ingredientes ativos em ambas as faces da folha ou mesmo ao longo da planta podem ocorrer e ocasionar níveis de mortalidade diferenciados, aspecto a ser mais bem investigado em futuros estudos.

\section{Seleção de nanoformulações}

Nanocápsulas em poli-\&-caprolactona (PCL): Após cinco dias da aplicação, as mortalidades causadas pelas duas nanoformulações contendo o polímero PCL, pelo Azamax ${ }^{\circledR}$ 1,2 CE (controle positivo) e pelos controles negativos (branco e água deionizada) foram baixas (não ultrapassando 4\%) (Figura 1). Aos dez dias após a aplicação, as mortalidades acumuladas (25-40\%) causadas pelas duas nanoformulaçóes foram superiores às verificadas nos controles negativos e semelhantes ao controle positivo (abaixo de 5\%). O incremento de mortalidade entre 10 e 15 dias foi inferior ao verificado na avaliaçáo anterior, sem diferença significativa entre o Azamax ${ }^{\circledR}$ 1,2 CE (54\%) e as nanoformulaçóes NC L5-1 e NCL 5-2 (cerca de 40\%).

A tendência de aumento da mortalidade do primeiro para o segundo período de avaliação e redução entre o segundo e o terceiro período pode estar associada ao tempo necessário para deslocamento dos compostos ativos (mínimo de 5 dias), bem como pela posterior degradação ou eliminação, após o décimo dia, dos ingredientes ativos no interior da planta ou mesmo pela maior tolerância das ninfas de $B$. tabaci biótipo $\mathrm{B}$ ao longo de seu desenvolvimento pós-embrionário. Os valores de mortalidade acumulada causada pelo Azamax ${ }^{\circledR}$ 1,2 CE e pelas nanoformulações em PCL foram próximos da mortalidade esperada ( $50 \%$ ), já que a concentração utilizada foi a $\mathrm{CL}_{50}$ estimada (em relação aos seus respectivos teores de azadiractina) para o óleo de nim, por meio desse mesmo modo de aplicação.

Nanocápsulas em poli- $\beta$-hidroxibutirato (PHB): Todas as nanoformulaçóes em $\mathrm{PHB}$ provocaram mortalidade maior que os controles negativos já na primeira avaliaçáo (5 dias após a aplicação), sem diferir do controle positivo (Azamax $\left.{ }^{\circledR} 1,2 \mathrm{CE}\right)$. Após 10 dias da aplicação, ocorreu elevação nos valores de mortalidade (65\% a 95\%), sem diferença entre as nanoformulaçóes e o controle positivo. Aos 15 dias após a aplicação, não foi verificado incremento significativo na ação inseticida, mantendo-se as nanoformulaçôes com eficácia similar ao controle positivo (Figura 2).

As variaçóes nos resultados com as diferentes formulaçóes possivelmente se devam a fatores climáticos (maior fotoperíodo, intensidade luminosa ou amplitudes térmicas), condiçôes que podem ter acelerado o rompimento dos polímeros e ou o metabolismo da planta, fazendo com que elas absorvessem mais rapidamente as moléculas inseticidas. O papel da radiaçáo ultravioleta e da temperatura na degradação de materiais poliméricos já foi reportado na literatura (Almeida \& Ferreira, 2006; Chandra \& Rustgi, 1998).

\section{Efeito residual das nanoformulações}

A mortalidade de ninfas de B. tabaci biótipo B ocasionadas pelas nanoformulaçóes selecionadas e pelo Azamax ${ }^{\circledR} 1,2 \mathrm{CE}$ seguiu o mesmo padrão nos cinco lotes de plantas (Tabela 4), variando em função da época de infestação em relação ao dia da aplicação (único para todos os lotes de plantas), com exceção para o lote infestado no dia da aplicação (DA). Aos 10 DAA (dias antes da aplicação), 5 DAA, 5 DDA (dias depois da aplicaçáo) e 10 DDA, as mortalidades ocasionadas pelo Azamax ${ }^{\circledR}$ 1,2 CE e pela nanoformulação preparada com PCL (NC L5-2) não diferiram entre si, mas foram superiores àquelas verificadas para a nanoformulaçáo preparada com PHB (NC L6-1). Já no lote DA, não houve diferença entre as mortalidades causadas pelo Azamax ${ }^{\circledR} 1,2 \mathrm{CE}$ e pelas duas nanoformulações selecionadas (Tabela 4). De modo geral, a maior mortalidade foi verificada com a infestaçáo feita 
Água $\square$ Branco $\square$ Azamax® $\square$ NCL5-1 $\quad$ NC L5 - 2

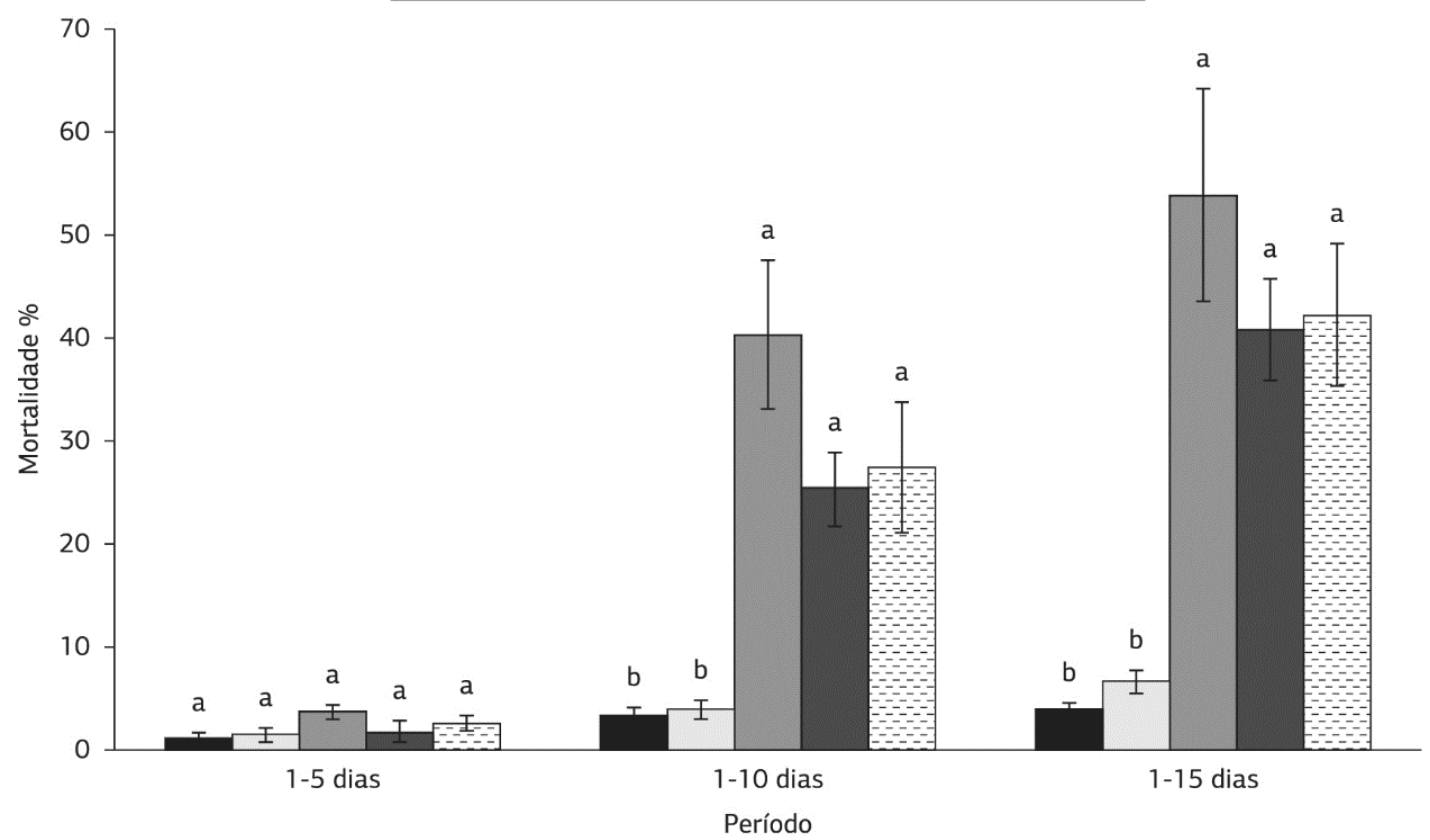

Figura 1. Mortalidade acumulada ( \pm erro padrão) de ninfas de Bemisia tabaci biótipo B em plantas de tomateiro tratadas com nanocápsulas à base de nim preparadas utilizando o polímero poli- $\varepsilon$-caprolactona (PCL), em três períodos de avaliação. Temperatura: $25,18 \pm 0,29^{\circ} \mathrm{C}, \mathrm{UR}$ : $63 \pm 0,8 \%$ e fotofase: 12,5 horas. Médias seguidas de mesma letra sobre as barras, em cada período de avaliação, não diferem entre si pelo teste $\mathrm{t}$ após correção de Bonferroni a 5\% de significância.

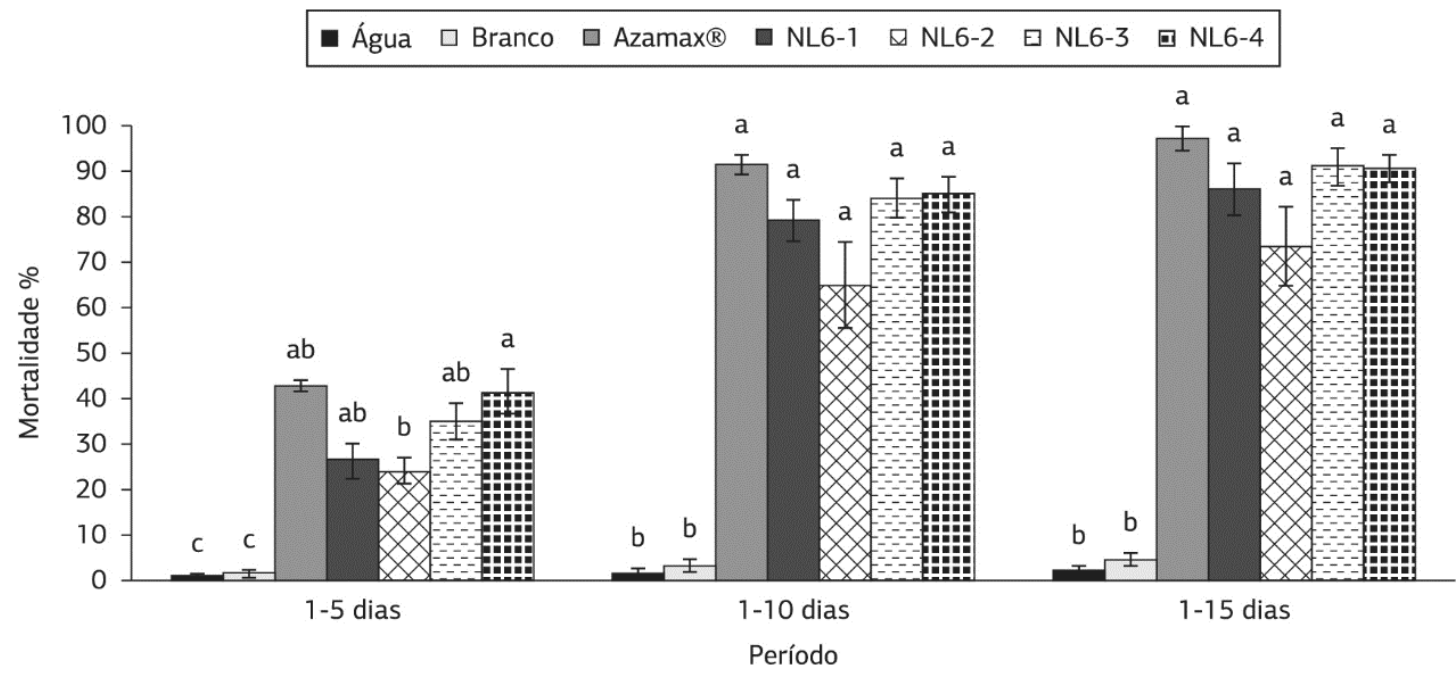

Figura 2. Mortalidade acumulada ( \pm erro padrão) de ninfas de Bemisia tabaci biótipo B em plantas de tomateiro tratadas com nanocápsulas à base de nim preparadas utilizando o polímero poli- $\beta$-hidroxibutirato $(\mathrm{PHB})$, em três períodos de avaliação. Temperatura: $24,99 \pm 0,23^{\circ} \mathrm{C}$, UR: $61,37 \pm 0,54 \%$ e fotofase: 13 horas. Médias seguidas de mesma letra sobre as barras, em cada período de avaliação, não diferem entre si pelo teste t após correção de Bonferroni a 5\% de significância.

aos 10 DAA, com tendência de redução nos dias próximos à aplicação.

Para o quinto lote de plantas (10 DDA), verificou-se que os compostos inseticidas das nanoformulaçôes e do Azamax ${ }^{\circledR} 1,2$ CE permaneceram ativos na planta por pelo menos 30 dias, já que a mortalidade acumulada 32 dias após a aplicação foi de cerca de 50\%, no mínimo. No entanto, comparativamente às formulaçôes comerciais disponíveis no mercado, o uso de nanoformulaçôes pode ser vantajoso, em termos de eficiência agronômica (custo e eficácia de controle), 
Tabela 4. Média ( \pm erro padrão) da mortalidade (\%) de ninfas de Bemisia tabaci biótipo B, aos 22 dias após a infestação, em plantas de tomateiro com diferentes épocas de infestação em relação ao dia da aplicação de nanoformulaçôes de derivados de nim aplicadas no solo em casa de vegetação. Temperatura: $27,48 \pm 0,13^{\circ} \mathrm{C}$, UR: $71,06 \pm 0,35 \%$ e fotofase de 13 horas

\begin{tabular}{|c|c|c|c|c|c|}
\hline \multirow[t]{2}{*}{ Tratamentos } & \multicolumn{5}{|c|}{ Época de Infestação } \\
\hline & 10 DAA & 5 DAA & DA & 5 DDA & 10 DDA \\
\hline NC L5-2 & $98,3 \pm 0,69 \mathrm{a}$ & $88,4 \pm 3,15 a$ & $75,3 \pm 3,54 \mathrm{a}$ & $80,1 \pm 4,43 \mathrm{a}$ & $59,9 \pm 7,36 a$ \\
\hline NC L6-1 & $70,6 \pm 3,70 \mathrm{~b}$ & $72,8 \pm 8,08 b$ & $51,2 \pm 5,82 a$ & $54,2 \pm 4,91 \mathrm{~b}$ & $49,0 \pm 4,55 b$ \\
\hline Azamax $^{\circledR} 1,2$ CE & $95,2 \pm 1,15 a$ & $90,2 \pm 4,87 a$ & $75,3 \pm 6,48 a$ & $72,9 \pm 7,48 \mathrm{a}$ & $58,8 \pm 2,09 a$ \\
\hline Branco1 (NC L5-2) & $9,4 \pm 0,90 c$ & $6,3 \pm 1,28 c$ & $10,4 \pm 1,99 \mathrm{~b}$ & $2,9 \pm 0,40 c$ & $4,9 \pm 0,81 c$ \\
\hline Branco 2 (NC L6-1) & $11,1 \pm 1,25 c$ & $6,4 \pm 0,69 c$ & $6,3 \pm 2,94 b$ & $4,0 \pm 0,64 c$ & $5,8 \pm 0,72 c$ \\
\hline Água deionizada & $10,5 \pm 1,52 c$ & $2,0 \pm 0,58 c$ & $8,8 \pm 1,13 b$ & $2,8 \pm 0,95 c$ & $3,1 \pm 0,49 c$ \\
\hline$p$ & $<0,0001$ & $<0,0001$ & $<0,0001$ & $<0,0001$ & $<0,0001$ \\
\hline
\end{tabular}

DAA $=$ Dias antes da aplicação. DA = Dia da aplicação. DDA = Dias depois da aplicação. Médias seguidas de mesma letra, nas colunas, não diferem entre si pelo teste t após correção de Bonferroni a $5 \%$ de significância.

devido à redução dos problemas de foto e termodegradação dos seus compostos ativos, uma das maiores limitaçóes para o uso de produtos naturais (Forim et al., 2013).

\section{CONCLUSÃO}

O óleo de nim aplicado via água de irrigação (solo) causa significativa mortalidade de ninfas de B. tabaci biótico B de modo dependente da concentração $\left(\mathrm{CL}_{50}=180,67 \mathrm{mg}\right.$ de azadiractina $\left.L^{-1}\right)$.

O produto Azamax ${ }^{\circledR}$ 1,2 CE não afeta a oviposição e o desenvolvimento embrionário da mosca-branca, quando aplicado via água de irrigação (solo).

Dependendo das condiçóes ambientais, as nanoformulaçóes NC L5-2 e NC L6-1 e o Azamax ${ }^{\circledR}$ 1,2 CE ocasionam mortalidade de no mínimo 50\% das ninfas, mesmo cerca de 30 dias após a aplicação.

\section{AGRADECIMENTOS}

À Prof. Dra. Marinéia de Lara Haddad, pelo auxílio nas análises estatísticas, ao Engenheiro Agrônomo Paulo César Bogorni, pelas recomendaçôes, e à Coordenação de Aperfeiçoamento de Pessoal de Nível Superior (CAPES), pela concessão de bolsa ao primeiro autor.

\section{REFERÊNCIAS}

Almeida, A. E. F. S., \& Ferreira, O. P. (2006). Poliuretana derivada de óleos vegetais exposta ao intemperismo artificial. Polímeros. Ciência e Tecnologia, 16, 252-256.

Amoabeng, B. W., Gurr, G. M., Gitau, C. W., Nicol, H. I., Munyakazi, L., \& Stevenson, P. C. (2013). Tri-trophic insecticidal effects of African plants against cabbage pests. PLoS One, 8, e78651. http://dx.doi. org/10.1371/journal.pone.0078651. PMid:24205287.
Brasil. Ministério da Agricultura, Pecuária e Abastecimento (2014) AGROFIT - Sistema de Agrotóxicos Fitossanitários. Brasília: Ministério da Agricultura. Recuperado em 28 de outubro de 2014, de http:// agrofit.agricultura.gov.br/agrofit_cons/principal_agrofit_cons.

Byrne, D. N., \& Bellows, T. S. Jr (1991). Whitefly biology. Annual Review of Entomology, 36, 431-457. http://dx.doi.org/10.1146/ annurev.en.36.010191.002243.

Carvalho, S. S., Vendramim, J. D., Pitta, R. M., \& Forim, M. R. (2012). Efficiency of neem oil nanoformulations to Bemisia tabaci (Genn.) biotype B (Hemiptera: Aleyrodidae). Semina. Ciências Agrárias, 33, 193-202.

Chandra, R., \& Rustgi, R. (1998). Biodegradable polymers. Progress in Polymer Science, 23, 1273-1335. Recuperado em 18 de novembro de 2009, de http://eidsbak.dhu.edu.cn/fzzx/pdf/file_3.pdf.

Devi, N., \& Maji, T. K. (2011). Neem seed oil: encapsulation and controlled release - search for a greener alternative for pest control. In M. Stoytcheva (Ed.). Pesticides in the modern world - pesticides use and management ( p. 192-232). Rijeka: InTech.

Eichelkraut, K., \& Cardona, C. (1989). Biología, cría masal y aspectos ecológicos de la mosca blanca Bemisia tabaci (Gennadius) (Homoptera: Aleyrodidae), como plaga del frijol común. Turrialba, 39, 55-62.

Ferreira, F. T. R., Vendramim, J. D., \& Forim, M. R. (2012). Bioatividade de nanoformulaçóes de nim sobre a traça-do-tomateiro. Ciência Rural, 42, 1347-1353. http://dx.doi.org/10.1590/S010384782012000800003 .

Finney, D. J. (1971). Probit analysis (3rd ed..). Cambridge: Cambridge University Press. 333 p.

Forim, M. R., Costa, E. S., Silva, M. F. G. F., Fernandes, J. B., Mondego, J. M., \& Boiça, A. L., Jr. (2013). Development of a new method to prepare nano-/microparticles loaded with extracts of Azadirachta indica, their characterization and use in controlling Plutella xylostella. Journal of Agricultural and Food Chemistry, 61, 9131-9139. http://dx.doi.org/10.1021/jf403187y. PMid:23991702.

Forim, M. R., Silva, M. F. G. F., Cass, Q. B., Fernandes, J. B., \& Vieira, P. C. (2010). Simultaneous quantification of azadirachtin and 3-tigloylazadirachtol in Brazilian seeds and oil of Azadirachta indica: application to quality control and marketing. Analytical Methods, 2, 860-869. http://dx.doi.org/10.1039/c0ay00008f. 
Isman, M. B., \& Grieneisen, M. L. (2014). Botanical insecticide research: many publications, limited useful data. Trends in Plant Science, 19, 140-145. http://dx.doi.org/10.1016/j.tplants.2013.11.005. PMid:24332226.

Isman, M. B., Miresmailli, S., \& Machial, C. (2011). Commercial opportunities for pesticides based on plant essential oils in agriculture, industry and consumer products. Phytochemistry Reviews, 10, $197-$ 204. http://dx.doi.org/10.1007/s11101-010-9170-4.

Leora Software (1987). Polo-PC: a user's guide to probit logit analysis. Berkeley: Leora Software.

Martinez, S. S. (Ed.) (2011). O nim: Azadirachta indica - natureza, usos múltiplos, produção. Londrina: Instituto Agronômico do Paraná. 205 p.

Mattoso, L.H.C., Medeiros, E.S., \& Martin, L. No. (2005). A revolução nanotecnológica e o potencial para o agronegócio. Revista de Política Agrícola, ano 14, 38-46.

Mordue (Luntz), A. J., \& Blackwell, A. (1993). Azadirachtin: an update. Insect Physiology, 39, 903-924. http://dx.doi.org/10.1016/00221910(93)90001-8.

Patel, H. M., Jhala, R. C., Pandya, H. V., \& Patel, C. B. (1992). Biology of whitefly (Bemisia tabaci) on okra (Hibiscus esculentus). Indian Journal of Agricultural Science, 62, 497-499.

Perlatti, B., Bergo, P. L. S., Silva, M. F. G. F., Fernandes, J. B., \& Forim, M. R. (2013). Polymeric nanoparticle-based insecticides: a controlled release purpose for agrochemicals. In S. Trdan (Ed.), Insecticides - Development of safer and more effective technologies (1st ed., p. 521-548). Rijeka: InTech.

Prabhaker, N., Toscano, N. C., \& Henneberry, T. J. (1999). Comparison of neem, urea, and amitraz as oviposition suppressants and larvicides against Bemisia argentifolii (Homoptera: Aleyrodidae). Journal of Economic Entomology, 92, 40-46.

Ribeiro, L. P., Vendramim, J. D., Bicalho, K. U., Andrade, M. S., Fernandes, J. B., Moral, R. A., \& Demétrio, C. G. B. (2013). Annona mucosa Jacq. (Annonaceae): a promising source of bioactive compounds against Sitophilus zeamais Mots. (Coleoptera: Curculionidae). Journal of Stored Products Research, 55, 6-14. http://dx.doi.org/10.1016/j. jspr.2013.06.001.

Ribeiro, L. P., Vendramim, J. D., Andrade, M. S., Bicalho, K. U., Fernandes, M. F. G. F., Vieira, P. C., \& Fernandes, J. B. (2014). Tropical plant extracts as sources of grain protectant compounds against Sitophilus zeamais. Neotropical Entomology, 43, 470-482. http://dx.doi.org/10.1007/s13744-014-0233-x.

SAS Institute (2011). SAS/STAT 9.3 user's guide. Cary: SAS Institute. $8621 \mathrm{p}$.

Schmutterer, H. (1990). Properties and potential of natural pesticides from the neem tree, Azadirachta indica. Annual Review of Entomology, 35, 271-297. http://dx.doi.org/10.1146/annurev.en.35.010190.001415. PMid:2405771.

Souza, A. P., \& Vendramim, J. D. (2005). Efeito translaminar, sistêmico e de contato de extrato aquoso de sementes de nim sobre Bemisia tabaci (Genn.) biótipo B em tomateiro. Neotropical Entomology, 34, 83-87. http://dx.doi.org/10.1590/S1519-566X2005000100012.

Stokes, J. B., \& Redfern, R. E. (1982). Effect of sunlight on azadirachtin: antifeeding potency. Journal of Environmental Science and Health. Part A, Philadelphia, 17, 57-65. http://dx.doi. org/10.1080/10934528209375019.

Sundaram, K. M. S. (1996). Azadirachtin biopesticide: a review of studies conducted on its analytical chemistry, environmental behavior and biological effects. Journal of Environmental Science and Health. Part. B, Pesticides, Food Contaminants, and Agricultural Wastes, 31, 913-948. http://dx.doi.org/10.1080/03601239609373045.

Toscano, L. C., Boiça, A. L. Jr, \& Maruyama, W. I. (2002). Fatores que afetam a oviposição de Bemisia tabaci (Genn.) biótipo B (Hemiptera: Aleyrodidae) em tomateiro. Neotropical Entomology, 31, 631-634. http://dx.doi.org/10.1590/S1519-566X2002000400017.

Villas-Bôas, G. V., França, F. H., Ávila, A. C., \& Bezerra, I. C. (1997). Manejo integrado da mosca-branca Bemisia argentifolii (Circular Técnica da Embrapa Hortaliças, 9). Brasília: Embrapa. 11 p. 